\title{
Evaluation of materials for artificial heart valves
}

\author{
G S BHUVANESHWAR, C V MURALEEDHARAN, A V RAMANI \\ and $M S$ VALIATHAN \\ Sree Chitra Tirunal Institute for Medical Sciences and Technology, Biomedical \\ Technology Wing, Poojapura, Trivandrum 695 012, India \\ MS received 19 December 1990
}

\begin{abstract}
The heart of a normal human being beats about 38 million cycles every year. An artificial heart valve, to perform at this rate in the adverse conditions inside the heart for 20 years or more, should be highly wear-resistant with excellent fatigue strength. Thus, the study of mechanical and physical properties of the materials intended for use in artificial valves becomes an inseparable part of the valve development process itself. The physical and mechanical requirements of the materials used in the Chitra heart valve have been evaluated by studying their water absorption, adhesive wear and abrasive properties. The mechanical durability of the device has been assessed by accelerated life cycle testing. The test systems developed for the above are described here. The results show UHMW-PE to be a highiy wear-resistant material suitable for the occluder. The accelerated wear tests show that the valve with Haynes-25 alloy cage and UHMW-PE disc has durability in excess of 50 years.
\end{abstract}

Keywords. Prosthetic heart valve; abrasive wear; adhesive wear; accelerated life cycle testing.

\section{Introduction}

Hufnagel and Harvey (1953) were the first to introduce the concept of an artificial valve by placing a caged-ball valve in the descending thoracic aorta. However, prosthetic (or artificial) heart valve replacement became a standard surgical practice only during 1960 with the first replacement of the aortic valve with a caged ball valve by Harken et al (1960) followed by replacement of the mitral valve (Starr and Edwards 1961). In the decade that followed, many designs of prosthetic valves have been tried-caged ball, caged disc, tear drop, double-caged ball, leaflet, tilting disc, etc made from materials ranging from metals like stellite and titanium to plastics like teflon, polypropylene, silicone rubber, polyurethane, etc: The various design changes were aimed at improving the performance of the valve and its durability. In this process, a set of material requirements gradually evolved and can be summarized as follows:

(i) Biological and chemical requirements

(a) Biocompatible-should be non-toxic and inert.

(b) Blood compatible-should not induce clots to be formed on its surfaces.

(c) Degradation and corrosion resistance in the body environment.

(ii) Physical and mechanical requirements

(a) Should be sterilizable.

(b) Should not absorb water or other body fluids and change size or shape. 
(c) Wear resistance and fatigue strength-should withstand the constant cycling of 38 million cycles per year for the life of the patient.

This period of development has seen the failure of many of the valve models due to the materials of construction not meeting the above requirements. The two notable ones are the ball-variance of the Starr-Edwards valve and the strut fractures of the Bjork-Shiley valve. Many materials especially polymers absorb water, lipids and other liquids upon prolonged immersion and swell or change shape. This can lead to failure of the valve as in the case of the Starr-Edwards valve due to fat absorption by the silicone rubber ball (Lefrak and Starr 1979). The heart of a normal human being beats about 38 million cycles every year. The materials used should be highly wear-resistant and have an excellent fatigue strength to perform in adverse conditions inside the heart for periods of 20 years or more. Over 300 valves of the Bjork-Shiley convexo-concave model have failed in patients due to fatigue fracture of one of the struts (Davis et al 1985; Joyce 1990).

The physical and mechanical test methods developed in this institute as part of the artificial valve development programme are described in this paper and the results discussed.

\section{Materials and methods}

The Chitra valve now incorporates a tilting disc of ultra high molecular weight polyethylene (UHMW-PE) inside a metallic cage of Haynes-25 alloy as shown in figure 1 . The polyester fabric sewing ring was used to stitch the valve to the heart muscle. The component materials were chosen for their known biocompatibility and engineering properties. The materials tried so far include:

Polymers Delrin (Polyacetal), UHMW-PE, Ekonol, Delrin-AF, DelrinST

Metals Titanium, Haynes-25 (cobalt based superalloy)

Ceramics Synthetic sapphire.

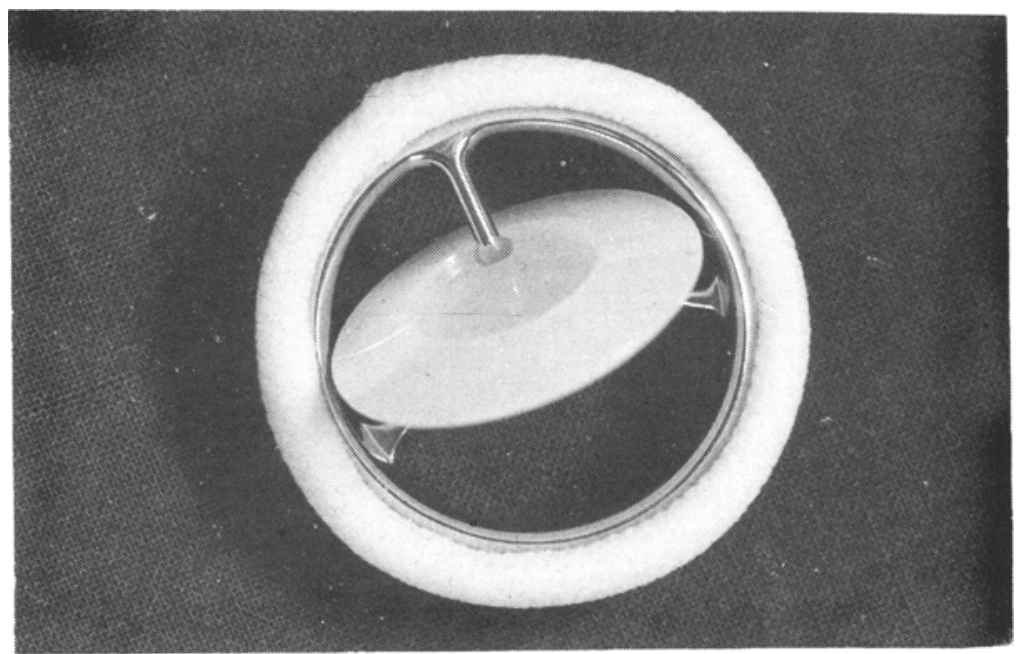

Figure 1. Chitra heart valve prosthesis. 
The materials required for biological and chemical requirements to be evaluated in animals were tested for toxicity and biocompatibility in small animals. The test methods are described by Vedanarayanan et al (1979). The prototype valves were implanted in sheep to determine their blood compatibility and to understand any handling and sterilization problems. The results of these tests will be presented elsewhere.

\subsection{Water absorption}

Water absorption of Delrin-ST, Delrin-AF and UHMW-PE was measured by soaking circular coin-like specimens $(25 \mathrm{~mm}$ diameter and $2 \mathrm{~mm}$ thick) in distilled water for periods up to 15 days. The samples were ultrasonically cleaned in $1 \%$ soap solution for $2 \mathrm{~min}$, rinsed in distilled water for $5 \mathrm{~min}$ and then dried in filter paper taking care to ensure that fibres of the paper do not adhere to the specimens. Five samples of each material were tested. The samples were taken out, the outer surface carefully dried and weighed at intervals of 24,96 and $360 \mathrm{~h}$. The weighings were carried out in an analytical balance (Sartorius) with an accuracy of $\pm 0.1 \mathrm{mg}$ and the weight gain noted.

\subsection{Wear testing of the materials}

The two main types of wear occurring in this situation are adhesive and abrasive wear. Adhesive wear is predominant when highly polished surfaces in contact articulate against each other (Rabinowicz 1965).

2.2a Adhesive wear by pin-on-wheel test: The test set-up (figure 2) used was a modified version of the ASTM recommended test for hip joint materials (ASTM

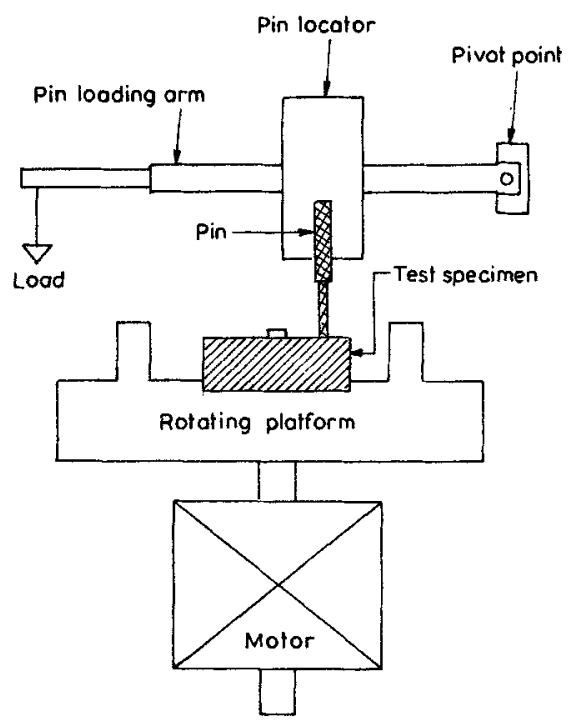

Figure 2. Pin-on-wheel adhesive wear test system. 
1986) consisting of a platform rotating at a constant speed of 55 RPM and a pinloading arm. The polymer specimen was a flat-ended circular disc of $25 \mathrm{~mm}$ diameter and $10 \mathrm{~mm}$ length. The metal pin, polished to the prosthetic implant quality of the valve cage and having a $3 \mathrm{~mm}$ diameter circular contact area slides against the surface of the disc. The loading arm was free to move vertically so as to follow the specimen as the wear occurs. The entire set-up was covered to eliminate any foreign particle coming between the wearing surfaces.

A load of 9.8 Newtons $(1 \mathrm{kgf})$ was applied along the longitudinal axis of the pin, so that the average contact stress was $1.373 \mathrm{MPa}\left(14 \mathrm{kgf} \mathrm{cm}^{-2}\right)$. The pin was loaded at a radial distance of $9 \mathrm{~mm}$ from the centre of the disc to produce a sliding speed of $50 \mathrm{~mm} / \mathrm{s}$. There are no lubricants between the sliding surfaces. A time totaliser records the duration of the test, which is $100 \mathrm{~h}$ so that sufficient wear occurs for accurate measurement of weight loss even in low wear materials. A minimum of three samples were tested for each material. The weight loss measured was converted to volume losses from known densities of test materials.

The material pairs tested were titanium pin on the different polymer discs and Haynes-25 alloy pin on UHMW-PE disc.

2.2b Abrasive wear by sand slurry test: The schematic of the set-up (figure 3) was modified from that of a polymer manufacturer (Himount Inc. 1986). The test specimen was mounted on a $0.5 \mathrm{hp}$ motor shaft. Alumina powder of 350-1000 $\mu$ particle size (20-40 BS-mesh) in an equal volume of water formed the abrasive slurry. The specimen was rotated at $3000 \mathrm{RPM}$ for $6 \mathrm{~h}$ inside the slurry. The height of the specimen from the bottom of the polystyrene container and the volume of the slurry were kept constant and the slurry changed after every test. A control sample of the same material was kept immersed in water for the same duration as the test and the weight gain of this was used to correct for water absorption of the material. This weight-loss was then converted to volume-loss as before. A minimum of five samples were tested for each material.

UHMW-PE was later chosen as the potential candidate material for valve discs. The process of fabrication of disc from raw material involves many thermal cycling

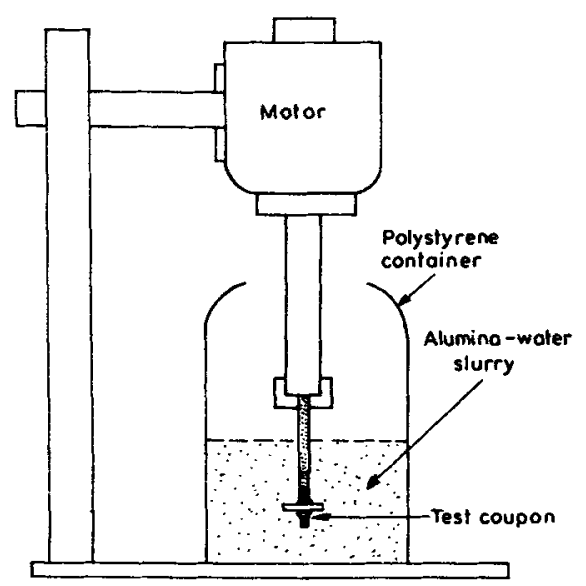

Figure 3. Sand-slurry abrasive wear test system. 
stages like compression moulding, die polishing, annealing, autoclaving of the valve for sterilization etc. The effect of thermal cycling on UHMW-PE was also studied by the above two methods.

\subsection{Accelerated durability test}

The durability of artificial heart valves was determined by accelerated life cycle testing to study their mechanical wear resistance and fatigue properties. To test new designs at normal heart rates, whether in mechanical systems or in animal models for periods over 10 years, is totally unrealistic. Several methods of accelerated testing of prosthetic valves have been used, including pneumatic cycling, several variations of mechanical cycling, hydraulic cycling and a combination of these (Fettel et al 1980).

Figure 4 is a schematic of the accelerated test system in use for the past 10 years. The hardware of this system presently in use is of third generation and many problems with the equipment have been minimized so that the test results can be interpreted with reasonable accuracy. Different pairs of cage and occluder materials were tested in this system to arrive at a suitable wear resistant combination. Five equally spaced valves were mounted on a stationary housing and covered with an acrylic chamber (figure 5). The test fluid (plain water treated with trace amounts of copper sulphate to control fungal growth) was supplied through the centre inlet of the test housing. A DC motor with a variable speed control drives the rotor inside the housing. The fluid at a pressure of $267 \mathrm{kPa}(200 \mathrm{mmHg}$, chamber A) was distributed by the rotor to sequentially actuate each of the five test valves. Two diametrically opposite fluid passages were incorporated in the rotor of the actual mechanism, so that a single revolution actuates each valve twice. This balances the rotor and reduces the number of revolutions, greatly increasing the life of seals and shaft bearings (for clarity, only one supply passage in the rotor is shown in figure 4).

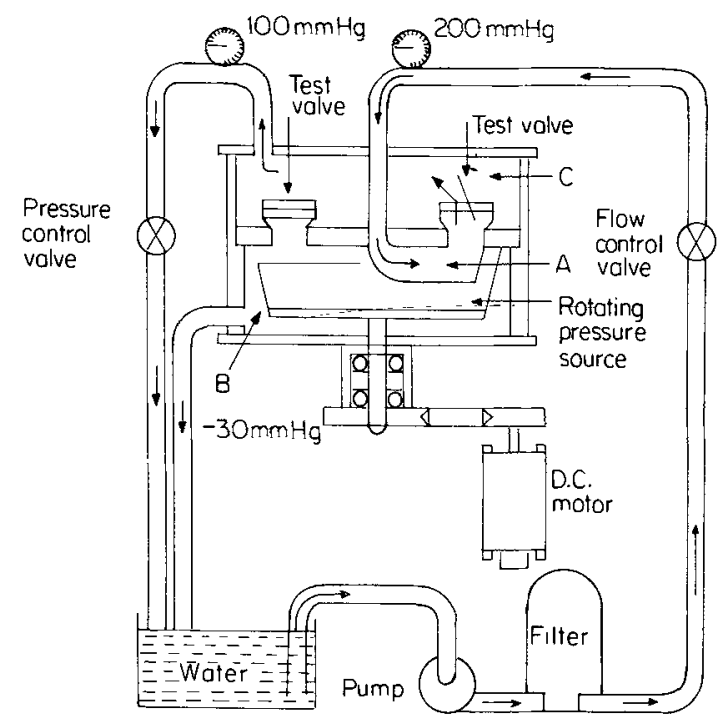

Figure 4. Accelerated life cycle test system. 


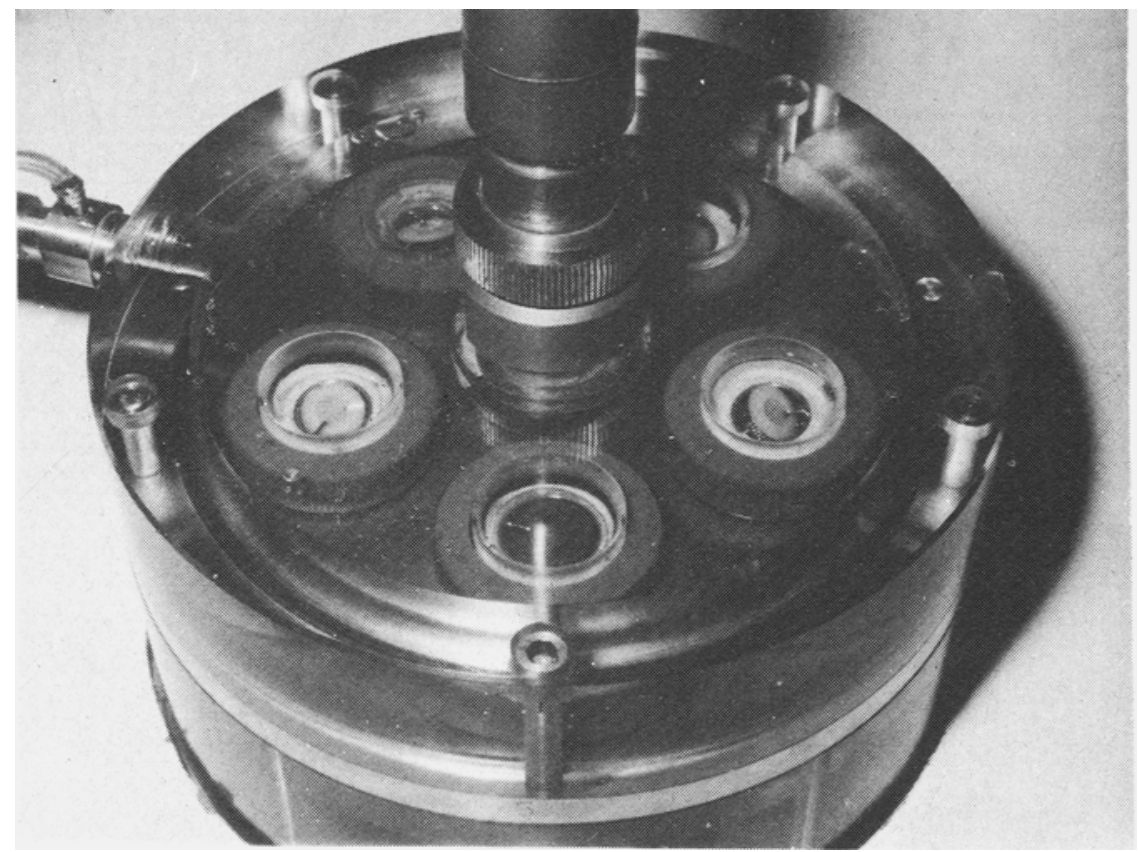

Figure 5. Test alkes mounted in the acceleratod tester.

Table 1. Valve models tested.

\begin{tabular}{lll}
\hline Valve model & $\begin{array}{c}\text { Cage } \\
\text { materit }\end{array}$ & $\begin{array}{c}\text { Disc } \\
\text { material }\end{array}$ \\
\hline $\begin{array}{l}\text { Chitra model II with inlet strut integral and outlet } \\
\text { strut EB welded. }\end{array}$ & $\begin{array}{l}\text { Titanium } \\
\text { Chitra model III all integral cage }\end{array}$ & Derlin \\
Chitra model IV all integral cage & Haynes-25 & Sapphire \\
Chitra model IV all integral cage & Sapphire \\
TiN coated & Hiynes-25 & Sapphire \\
Chitra model V all integral cage & Titanium & UHMW-PE \\
Chitra model Va all integral cage & Haynes-25 & UHMW-PE \\
Bjork-Shley standard model & Stellite & Pyrolitic carbon \\
\hline
\end{tabular}

The test fluid then passes through the valve into the outer chamber $C$ and returns to the reservoir. The portion of the rotating member not containing the fluid passage was relieved, thus allowing the residual fluid in the inner chamber $\mathrm{B}$ to drain into the reservoir resulting in a minimal pressure at the valve inlet in the absence of inlet supply. The fluid was pumped through a $10 \mu$ filter to remove foreign particles. Pressures control valves and monitoring gauges were placed as shown in figure 4 . The test valves were mounted with their sewing rings stitched to silicone rubber supports to isolate and damp their vibrations during cycling.

Table 1 shows the valve models tested in this system for various periods and their durability assessed. The wear of the valve components was measured by weighing 
the components and cage/disc assembly to an accuracy of $\pm 0.1 \mathrm{mg}$ in a single pan electronic balance (Sartorius). The cage and disc were weighed separately before assembly. The assembly was weighed again after inspection. Control weights of titanium were used to monitor the reliability and consistency of the weighing balance over the prolonged test period.

The test valves were cycled at $800-840$ times a minute. The calibration of the d.c. motor speed controller was periodically checked with a stroboscope. The valves were removed after 1, 2, 5, 10, 20, 40 million cycles and thereafter at intervals of 40 million cycles. At these instances, the assemblies were removed from their sewing ring holder, cleaned, degreased and dried before weighing.

The end of the cycling of any valve is determined when (i) there is a failure of any of its components, (ii) excessive wear is noticed and the valve is expected to fail very soon or when (iii) the valve reaches 400 million cycles without failure.

At the end of the test, the valves were dismantled and the components weighed again. They were also inspected for signs of wear and other degradation. The volume of wear was calculated from the weight loss and the density of the material. During cycling, since the cage and disc cannot be weighed separately, the weight loss was attributed to the component which wears most. The error due to this was found to be small as borne out by the final weighings.

The extrapolation of the wear data obtained from accelerated wear testing to predict the actual implant durability depends on the relation of the wear occurring in vivo to that measured in the test system. To assess this factor, valves implanted in sheep for various intervals of time were accurately monitored for weight loss. The number of cycles completed was estimated by assuming that, on an average, the heart of the animal beats at 70 per minute.

\section{Results}

\subsection{Water absorption}

Figure 6 is the data obtained from water absorption tests. The results show the higher water absorption of Delrin based polymers compared to the UHMW-PE.

\subsection{Water tests}

Figure 7 shows the results obtained from the adhesive wear test. The reported

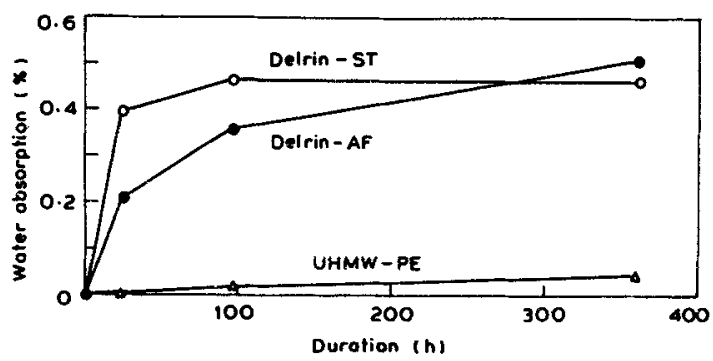

Figure 6. Results of water absorption test. 


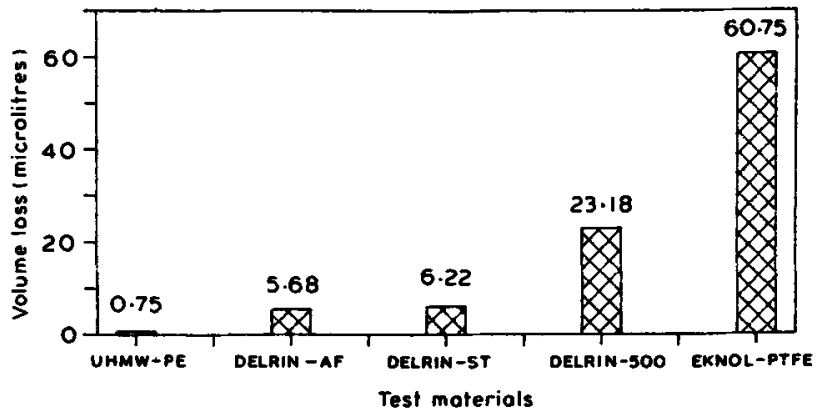

Figure 7. Results of the pin-on-wheel wear test.

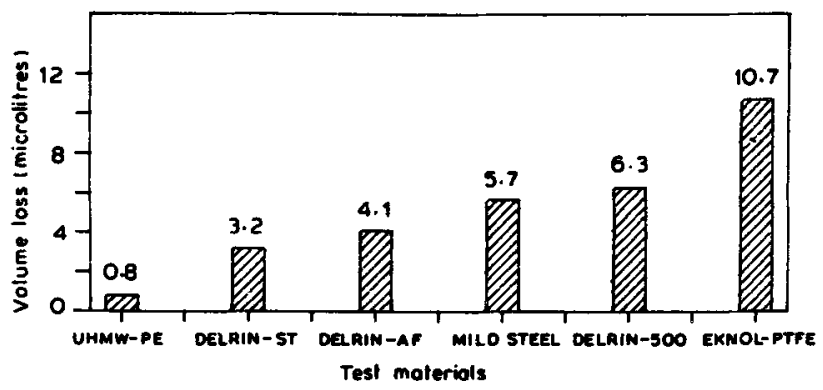

Figure 8. Results of the sand-slurry wear test.,

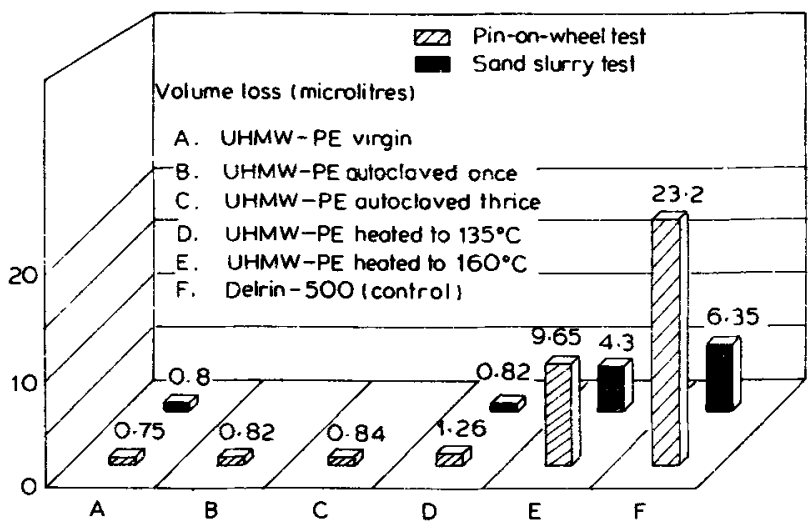

Figure 9. Effect of thermal cycling of UHMW-PE on its wear.

volume losses are the combined losses from the pin and the wheel.

The results from the sand slurry test are given in figure 8 . Here mild steel was used as the control.

The results from tests for studying the wear behaviour of UHMW-PE undergoing thermal cycling are shown in figure 9. These results establish that any thermal cycling of the material above $135^{\circ} \mathrm{C}$ can cause deterioration in its wear 
properties (the reported glass transition temperature of UHMW-PE is $136-138^{\circ} \mathrm{C}$ ). These tests showed that steam sterilization does not considerably change the wear properties of UHMW-PE.

\subsection{Accelerated life cycle testing}

Figure 10 shows the relative wear rates of the various combinations tested during the last 8 years. The lowest wear rate is for the Bjork-Shiley valve with the Stellite/Pyrolytic carbon combination. The titanium sapphire combination shows an extremely high wear rate. In fact, this combination failed in animals between 1 and 3 months due wear of the titanium cage.

The TiN-coated Haynes- 25 cage gives the best durability when sapphire disc is used. UHMW-PE with Haynes-25 combination turned out to be the best. The wear rate was marginally higher than the proven Bjork-Shiley valve and extrapolation gave an estimate of durability in excess of 50 years.

Table 2 shows the weight loss of valves recovered from animal implantations and the corresponding weight loss interpolated from accelerated wear testing data.

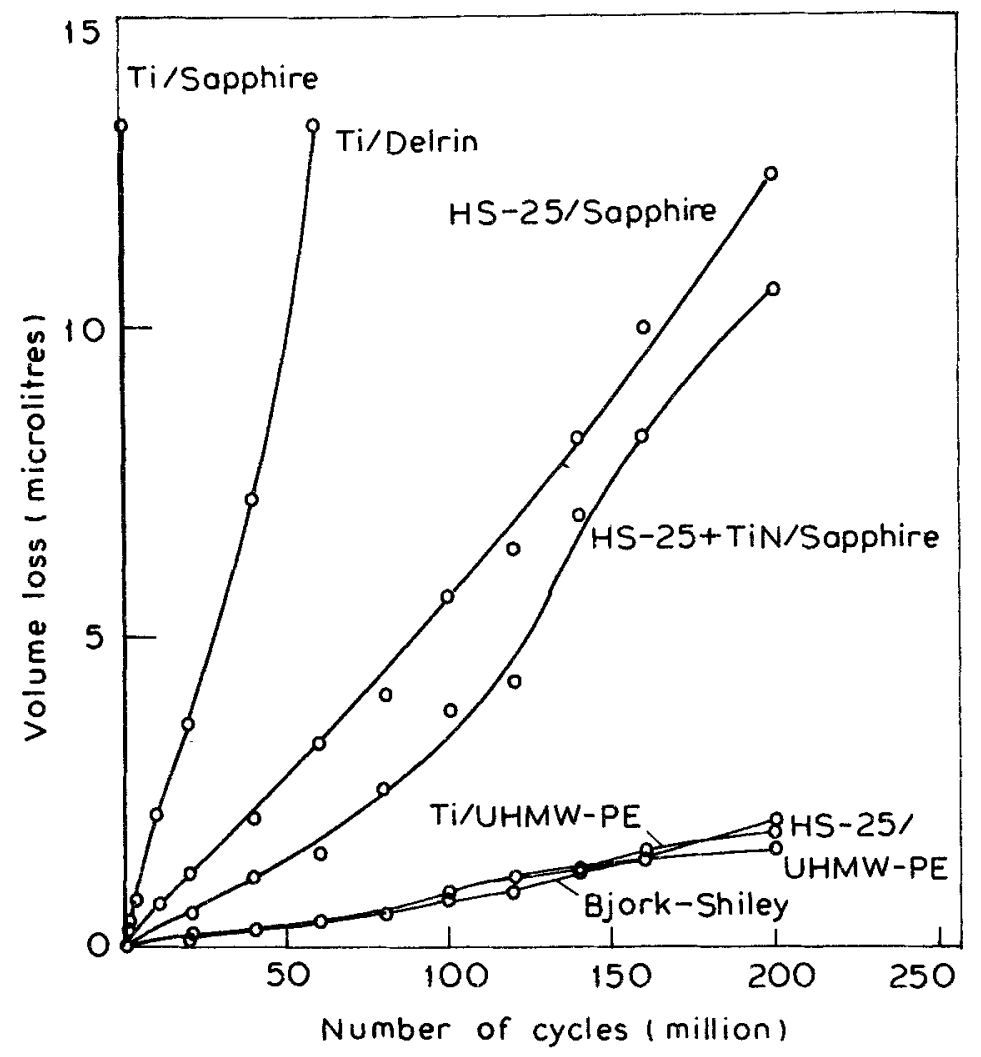

Figure 10. Results of accelerated life cycle testing. 
Table 2. Weight loss of valves from animal implants.

\begin{tabular}{lccccc}
\hline & \multicolumn{2}{c}{ Animal implantation } & & \multicolumn{2}{c}{ Accelerated testing } \\
\cline { 2 - 3 } \cline { 6 - 7 } Valve model & $\begin{array}{c}\text { Cycles } \\
\text { (millions) }\end{array}$ & $\begin{array}{c}\text { Wt loss } \\
(\mathrm{mg})\end{array}$ & & $\begin{array}{c}\text { Cycles } \\
\text { (millions) }\end{array}$ & $\begin{array}{c}\text { Wt loss } \\
\text { (mg) }\end{array}$ \\
\hline Ti TiN cage/sapphire disc & 5.9 & 16.9 & & 0.6 & 16.8 \\
Haynes 25 cage/sapphire disc & 11.55 & 5.9 & & 11.55 & 5.2 \\
$\begin{array}{l}\text { TiN coated HS-25 cage/ } \\
\text { sapphire disc }\end{array}$ & 50.5 & 20.4 & & 50.5 & 19.1 \\
\hline
\end{tabular}

\section{Discussion}

\subsection{Absorption}

The low water absorption of UHMW-PE ensures that the disc will not unduly swell and change shape like the Delrin disc occluder of the first Bjork-Shiley model (Teuvo and Penth 1974).

\subsection{Wear}

The pin-on-wheel and sand-slurry wear tests indicated that UHMW-PE is an extremely good material for heart valve occluders. These results are also confirmed by the accelerated durability testing of valves with UHMW-PE discs. They further helped to establish the correct processing cycles for its fabrication. Though steam sterilization does not create noticeable changes in its wear properties, it is advisable to minimize the thermal cycling of the assembled valve as a measure of precaution. Fabrication of prototype valves followed by accelerated durability testing and animal trials will take a minimum of $6-12$ before any meaningful data become available. These tests can quickly screen more material combinations and help reduce the development time.

\subsection{Mechanical durability}

Many difficulties were encountered with accelerated testing, most of which were related to interpreting results and relating them to clinical application. Wear rates were generally greater at the beginning of the testing and tend to level off after a short "wear in" period, once the mating parts have seated. Because structural fatigue failures are particularly difficult to predict, projections of valve life based on wear rate projections would not be appropriate if structural fatigue were the limiting factor.

Accelerated testing inherently imposes unrealistically severe conditions because of (a) the inability to achieve adequate system damping, (b) increased pressures that are required to achieve full valve excursion, (c) inferior lubricating properties of the test fluid and (d) high frequencies imposing stresses not found at lower rates (Fettel et al 1980).

The durability of the test apparatus itself is a significant problem when one 
considers that it must outlive a relatively simplistic device designed to withstand an equivalent of 38 million cycles per year of use for over 20 years or more. All these factors must be considered both during the design of the test system and the subsequent evaluation of results.

Accurate prediction of device durability is of paramount importance in the development of life-saving implants like artificial heart valves. The present test system developed here has proved to be reliable in terms of long-term performance. The wear rates observed in this system give a good $1: 1$ correspondence to the wear rates obtained from implanted devices.

Thus the study of mechanical and physical properties of materials intended for use in artificial valves, becomes an inseparable part of the valve development process itself. In the Indian context, the durability of the valve is all the more important because the average age of an Indian patient undergoing valve replacement is between 20 and 30, whereas this is in the sixties in developed countries. Having gone through 3 models during the last 10 years with the failure of the first two, this set of test methods has been developed to ensure that the material requirements of the device are met.

The Bjork-Shiley standard valves have been in clinical use since 1971 and have a good track record of durability. Their current durability is estimated to be 400 years (Fettel et al 1980). The wear rates of Haynes-25/UHMW-PE combination are marginally higher than that of the Bjork-Shiley. Since it is the disc that wears in these two models unlike those with Sapphire, the wear gets distributed over the surface of the disc as it rotates during working. Hence, for a given volume loss of wear, the thickness of the component worn out is very much smaller than it would be, if the cage struts were to wear. Clinical use of UHMW-PE in artificial hip joints over the last 25 years has shown this material to be extremely stable in the body environment. Considering all this, it is clear that the Haynes-25/UHMW-PE combination should easily last for over 50 years of implant life.

However, it should be emphasized that all this simulated testing does not preclude or eliminate the need for animal trials of the device. Early on in our development effort, the titanium/sapphire combination showed acceptable wear rates in the accelerated life cycle test. However, in animal implants, this model repeatedly failed due to strut wear of the metallic cage between 1 and 3 months. Though the problem was traced to the lubricating effect of glycerine in the test fluid of the accelerated system, it is clear that one cannot exactly simulate the in vivo conditions. Another example is the high failure rate of the Bjork-Shiley convexoconcave valve in patients due to strut fracture (Davis et al 1985; Joyce 1990), though their earlier standard model had an excellent record of safety. This problem was consequent to the change in shape of the disc. Design changes, however minor, can lead to deleterious effects and hence necessitates a full cycle of retesting in critical implantable devices. As mentioned in $\S 2$, the Chitra valves are finally evaluated by implantation in sheep. At the time of writing this paper, 5 sheep with the Haynes-25/UHMW-PE valves are alive and doing well at 3 months. The details of this study will be published in future.

\section{Acknowledgement}

The authors are grateful to the Tool-room and Engineering Services divisions of the 
Institute for their unstinted support in the fabrication of test samples, prototype valves and the test systems.

\section{References}

ASTM Report 1986 American Society for Testing and Materials; F732-82

Davis K, Myers J L, Pennock J L and Thiele B L 1985 Ann. Thorac. Surg. 4066

Fettel B E, Johnston D R and Morris P E 1980 Medical Instrum. 14161

Harken D E, Soroff H S, Taylor W J, Lefemine A A, Gupta S K and Lunzer S $1960 \mathrm{~J}$. Thorac. Cardiovasc. Surg. 40744

Himount Inc. 1986 Himount USA Inc. technical literature-500-657c

Hufnagel C A and Harvey P 1953 Bull. Georgetown Univ. 660

Joyce C 1990 New Scientist 125:1709 22

Lefrak E A and Starr A 1979 in Cardiac valve prosthesis (New York: Appleton-Century-Crofts) pp. 8791

Rabinowicz E 1965 in Friction and wear of materials (New York: John Wiley and Sons) pp. 113-118, $125-130,167$

Starr A and Edwards M L 1961 Ann. Surg. 154726

Teuvo K I L and Penth K 1974 J. Thorac. Cardiovasc. Surg. 6866

Vedanarayanan P V, Rathinam K and Fernandez A G 1979 Preliminary investigations on the biocompatibility/safety of three candidate materials intended for the fabrication of a prosthetic heart valve: Presented at the 31 st Indian Pharmaceutical Congress, Baroda 